\title{
Understanding the Mediating Role of Anxiety and Depression on the Relationship Between Perceived Stress and Sleep Quality Among Health Care Workers in the COVID-19 Response
}

\author{
Yi Luol,* \\ Suding $\mathrm{Fei}^{1, *}$ \\ Boxiong Gong ${ }^{2}$ \\ Tongda Sun ${ }^{3}$ \\ Runtang Meng $\mathbb{D}^{4}$ \\ 'School of Nursing, Ningbo College of \\ Health Sciences, Ningbo, Zhejiang, \\ People's Republic of China; ${ }^{2}$ Department \\ of Nursing, Taihe Hospital, Hubei \\ University of Medicine, Shiyan, Hubei, \\ People's Republic of China; ${ }^{3}$ Research \\ Institute of Health Service, Ningbo \\ College of Health Sciences, Ningbo, \\ Zhejiang, People's Republic of China; \\ ${ }^{4}$ School of Public Health, Hangzhou \\ Normal University, Hangzhou, Zhejiang, \\ People's Republic of China
}

*These authors contributed equally to this work
Correspondence: Runtang Meng School of Public Health, Hangzhou Normal University, No. 2318, Yuhangtang Road, Yuhang District, Hangzhou,

Zhejiang, 3III2I, People's Republic of China

Email mengruntang@hznu.edu.cn
Objective: There is an increasing amount of evidence exploring the adverse effects of perceived stress or anxiety and depression independently on sleep quality during the COVID19 outbreak, although the underlying mechanisms are unclear. The aim of the current study was to explore the role of anxiety and depression as a potential mediator between perceived stress and sleep quality among health care workers.

Methods: Data were collected through an online survey using the snowball sampling method and comprised 588 current health care workers in Zhejiang and Hubei provinces, China, from February to March 2020. We administered the Sleep Quality Questionnaire (SQQ), the Perceived Stress Scale (PSS-10), the Patient Health Questionnaire (PHQ-4) and the sociodemographic characteristics and COVID-19-related characteristics questionnaire. Structural equation modelling (SEM) was used to examine the direct and indirect relationships between perceived stress, anxiety and depression, and sleep quality.

Results: The average scores for sleep quality and perceived stress were 16.01 (95\% CI $[15.40,16.57])$ and 15.46 (95\% CI $[15.05,15.87])$, respectively. The positive rates of anxiety and depression symptom tests were $9.86 \%$ and $10.37 \%$, respectively. The SEM results indicated that the original relationship between perceived stress and sleep quality was beta $=0.52(P<0.001)$ and reduced to beta $=0.25(P=0.045)$ while introducing anxiety and depression as mediating variables. Perceived stress was positively associated with anxiety and depression (beta $=0.78, P=0.014$ ), and anxiety and depression were positively associated with sleep quality (beta $=0.42, P<0.001$ ).

Conclusion: Poor sleep quality and high perceived stress were common during the COVID19 crisis. Reducing perceived stress could help reduce anxiety and depression symptoms, thereby improving sleep quality among health care workers. In an attempt to promote psychological resources, we should perhaps take multiple measures, including personal tailored intervention and organizational humanistic concern.

Keywords: health care workers, sleep quality, anxiety, depression, perceived stress, COVID-19

\section{Introduction}

Globally, to date (10 September 2021), there have been 223,022,538 confirmed cases of COVID-19, including 4,602,882 deaths, reported to the World Health Organization (WHO). ${ }^{1}$ The rapid spread of COVID-19 poses a grave health threat and has serious socioeconomic implications for all. ${ }^{2}$ In response to this global outbreak, many countries have adopted a variety of measures, such as social 
distancing, self-isolation and travel restrictions, or even forced lockdown. The COVID-19 crisis has almost certainly placed a significant strain on health systems across the globe and has exposed health care workers to an unprecedented threat. $^{3,4}$ Not surprisingly, health care workers are not only placed at the core of the pandemic but are in a particularly vulnerable position. ${ }^{4}$ They are predisposed to a number of risks: heavy workloads, unpredictable work patterns, and a higher risk of infection, which might have consequences on their health and wellbeing. ${ }^{5,6}$ Moreover, in comparison to the general population, health care workers are facing increased professional and personal responsibilities during the pandemic, which may lead to an additional psychological burden. ${ }^{7}$

Multiple work stressors increase the risk of adverse mental health outcomes, including but not limited to psychological distress (fear, stress, anxiety, depression, exhaustion, post-traumatic stress disorder (PTSD)) and sleep dysfunction (poor sleep quality, sleep debt, insomnia). Indeed, during a crisis such as the current COVID-19 pandemic, the quality of sleep of health care workers becomes essential. ${ }^{4}$ However, there is no single perfectly reliable criterion for defining sleep or even sleep quality because it is generally defined as a complex state. ${ }^{8}$ Ample sleep, a balanced diet, and physical activity are three fundamental needs. ${ }^{9}$ Ample sleep is summarized by at least three aspects: adequate sleep quantity (quantity), good sleep quality (quality), and regular sleep patterns (circadian rhythm). ${ }^{10}$ Good sleep is vital to good health. $^{11}$ Subjective sleep quality complaints may be a consequence of disease. ${ }^{12}$ Sleep quality is an important signal and sign of the transition between health and disease. Poor sleep quality, sleep debt, acute/chronic stress, and other mental health problems could impair cognitive functioning and weaken decision-making ability, thereby reducing clinical work efficiency and increasing the risk of medical errors, which may hinder the fight against COVID-19 and could result in a lasting effect on overall well-being. ${ }^{13-18}$ Hence, the toll of the crisis has been heavy on health care workers.

Health care services are widely recognized as a challenging occupation; health care workers, who receive rigorous training to prepare themselves for this occupation, report a higher level of sleep disturbance during the COVID-19 pandemic. For instance, a 2021 meta-analysis reported that worldwide, the prevalence of sleep disturbance has been estimated to be between 18.4 and $84.7 \%$ in health care workers and $17.65-81 \%$ in the general population. ${ }^{19}$ Exposure to the COVID-19 pandemic in the workplace could act as a precipitating factor of a hyperarousal state, which could lead to a higher incidence of sleep disturbance and other sleep disorders when compared with the general population. ${ }^{3}$ Sleep dysfunction is often accompanied by psychological distress symptoms among health care workers during the COVID-19 pandemic. $^{20-22}$ Studies have shown that work stressors from COVID-19 can induce mild to severe levels of anxiety, depression, exhaustion, PTSD and sleep dysfunction. ${ }^{15,23-26}$ Alternatively, another argument for there is still little evidence of an increase in sleep disturbances in health care workers during the outbreak; ${ }^{27}$ health care workers had poor sleep status, even before COVID-19. Work stressors can have on sleep, but lack or poor quality of sleep has on resilience and stress, which is cyclical relationship. ${ }^{28}$ In the long term, we are addressing the urgent needs of protecting the sleep health, mental health and well-being of health care workers. ${ }^{29,30}$ However, evidence is limited regarding the impact of the current pandemic on sleep dysfunction in health care workers derived from coronavirus stress, particularly the underlying mechanism of both variables.

Despite the strong relationship between psychological health and sleep, little is known about the mechanism of the relationship between COVID-19 stress, anxiety and depression, and sleep quality. Based on the current literature, a priori hypotheses are that high stress in health care workers will reduce sleep quality, mainly indirectly through anxiety and depression during the COVID-19 epidemic. Considering the available evidence that anxiety and depression could act as a risk factor to intensify the negative consequences of perceived stress on health care workers, the aim of this study was to explore the mediating role of anxiety and depression in the relationship between perceived stress and sleep quality. Meanwhile, the current study revealed influencing factors on the mental health of health care workers during the COVID-19 crisis. The findings will help to better understand factors associated with perceived stress, anxiety and depression, and sleep quality, specifically the influencing mechanism of anxiety and depression on both variables of health care workers. These findings might have significant implications for effective interventions designed to improve sleep quality and well-being of health care workers.

\section{Methods}

\section{Participants and Procedure}

From February 25 to March 3, 2020, for approximately a week, we recruited health care workers from across 
Zhejiang and Hubei provinces to complete the online survey. At the beginning of the COVID-19 outbreak, a snowball sampling method was used to recruit participants anonymously. ${ }^{31}$ The self-selection survey was distributed through a dozen department heads, and the respondents chose to participate by clicking on a link or scanning a quick response (QR) code. Each respondent and her or his department head knew each other. Inclusion criteria: (1) health care workers, (2) agreed to participate in the survey, and (3) could read a Chinese questionnaire. Exclusion criteria: (1) would not be allowed to submit survey responses using the same IP address, (2) who were not in position at the time of the survey due to any leave of absence and (3) invalid response such as short response time and longstring. Participants included medical doctors, registered nurses, medical technicians (eg, pharmacists, therapists, laboratory technicians) and administrators (eg, department directors, nursing supervisors). Prior to data analyses, we excluded $2(0.3 \%)$ of the initial respondents because they were identified as invalid responses. Our final sample contained 588 submitted surveys with no missing data.

\section{Measures}

Sociodemographic Characteristics and COVID-19Related Characteristics Questionnaire

The sociodemographic characteristics included gender (male and female), province (Zhejiang, Hubei, and others), marital status (single, married, divorced, widowed), occupational categories (medical doctor, registered nurse, medical technician, administrator), professional title (unknown, junior, intermediate, vice-senior or senior), and educational level (technical secondary school or below, college degree, bachelor's degree, master's degree or above).

The COVID-19-related characteristics include departmental function (designated hospitals, community health centre, other medical institutions), if work affairs were the same as before (identical, basically consistent, inconsistent), job category (direct contact with confirmed patients and/or body fluid, possible contact with confirmed patients and/or body fluid, direct contact with suspected patients and/or body fluid, possible contact with suspected patients and/or body fluid, have no contact with any confirmed and suspected patients and/or body fluid), adequate protection (No or Yes), quarantined status currently (No or Yes), the burden of family care
(No and Yes), and work experience in response to outbreaks (No or Yes).

\section{Sleep Quality Questionnaire (SQQ)}

The Sleep Quality Questionnaire (SQQ) was used to assess sleep quality. ${ }^{32}$ Participants responded to ten items about their subjective experience of sleep in the past month. They rated the extent of agreement with each 5-point Likert scale item, ranging from 0 (strongly disagree) to 4 (strongly agree). Individual scores on the SQQ can range from 0 to 40, with higher composite scores indicating poorer sleep quality. The Chinese version of the SQQ (SQQ-C) was adapted and validated for the first time by a doctoral program of the corresponding author and exhibited satisfactory psychometric properties using a large sample survey among university students, medical workers, and general patients. ${ }^{33,34}$ Cronbach's $\alpha$ coefficient for the SQQ-C was 0.901 (95\% CI [0.889, 0.913]), suggesting optimal internal consistency.

\section{Perceived Stress Scale (PSS-10)}

The Perceived Stress Scale (PSS) is a brief scale of stress perceptions and measures the degree to which one perceives three aspects: uncontrollable, unpredictable, and overloading. ${ }^{35}$ There were three forms: fourteen items (PSS14), ten items (PSS-10) and four items (PSS-4). ${ }^{36}$ Respondents were required to respond to each item on a 5-point Likert scale, ranging from 0 (never) to 4 (very often), with higher composite scores indicative of greater levels of perceived stress within the past month. The current study used the PSS-10, and thus, individual scores on the PSS can range from 0 to 40 . The Chinese version of the PSS-10 (PSS-10-C) established adequate reliability and validity statistics when used in a sample of Chinese policewomen. ${ }^{37}$ Cronbach's $\alpha$ coefficient for the PSS-10-C was 0.815 (95\% CI $[0.792,0.837])$, suggesting satisfactory internal consistency.

\section{Patient Health Questionnaire (PHQ-4)}

A self-report version of the Primary Care Evaluation of Mental Disorders (PRIME-MD) called the Patient Health Questionnaire (PHQ) was developed and validated in two large studies. ${ }^{38}$ The Generalized Anxiety Disorder scale (GAD) is derived from the original PHQ. The GAD-2 and PHQ-2 altogether consist of the PHQ-4 for detecting probable generalized anxiety disorder and major depressive disorder, respectively. Each scale rates the severity of each item over the preceding 2 weeks on a four-point Likert scale $(0-3 ; 0=$ not at all, $3=$ nearly 
every day). ${ }^{39}$ A score of each scale ranges from 0 to 6 . When screening for anxiety disorders or depressive disorders, a recommended cut-off point for further evaluation is a score of 3 or greater. The Chinese version of the PHQ-4 (PHQ-4-C) and its instruction manual are now publicly available from the Patient Health Questionnaire (PHQ) Screeners (Retrieved from: https://www.phqscre eners.com). Cronbach's a coefficient for the PHQ4-C was 0.870 (95\% CI [0.852, 0.886]), suggesting satisfactory internal consistency.

\section{Data Analyses}

The authors managed the data with EXCEL (version 2010; Microsoft Corporation, Redmond, WA, USA) software. SPSS plus Amos (version 18.0; SPSS Inc., Chicago, IL, USA) and JASP (version 0.12.2; JASP Team, University of Amsterdam, Amsterdam, The Netherlands) were adopted to analyse the data. Frequencies were used to describe the sociodemographic characteristics and COVID-19-related characteristics. The mean (95\% confidence interval, 95\% CI) represented the mean value; analysis of variances or chisquare test was used to compare values among groups. We estimated the strength of the pathways between perceived stress, anxiety and depression, and sleep quality using structural equation modelling (SEM) with maximum likelihood estimation (MLE). An acceptable goodness-of-fit (GOF) model was indicated by the root mean square error of approximation (RMSEA, 90\% CI) $<0.08$, standardized root mean residual (SRMR) $<0.08$, goodness of fit index (GFI) $>0.90$, normed chi-square (NC) $<$ 2.0-3.0, Tucker-Lewis index (TLI) $>0.90$, comparative fit index $(\mathrm{CFI})>0.90$, parsimony goodness-of-fit index $(\mathrm{PGFI})>0.50$, and parsimony normed fit index $(\mathrm{PNFI})>$ $0.50 .^{40-42}$

\section{Ethics Statement}

Participation in the study was voluntary and anonymous, and participants could opt out at any time while responding to these survey questions to ensure full respect and protection of individual privacy throughout this process. Do not allow the data to be associated with a specific person. Informed consent was obtained from all participants enrolled in the study. This study meets the relevant requirements of the Declaration of Helsinki and its revised version. ${ }^{43}$ The Ethics Committee of Ningbo College of Health Sciences reviewed and approved the protocol.

\section{Results \\ Sociodemographic Characteristics and COVID-19-Related Characteristics}

Sociodemographic characteristics and COVID-19-related characteristics are described in Table 1. Regarding sociodemographic characteristics, $75.68 \%$ of respondents were female. Of the respondents, $60.37 \%$ worked in Zhejiang Province, $32.31 \%$ worked in Hubei Province, and $7.31 \%$ worked in other provinces. A total of $17.69 \%$ of participants surveyed were single, $80.95 \%$ were married, and $1.36 \%$ were divorced. Among all participants, $40.65 \%$ were medical doctors, $45.24 \%$ were registered nurses, $10.71 \%$ were medical technicians, and $3.40 \%$ were administrators. A total of $3.57 \%$ had unknown titles, $31.29 \%$ had junior titles, $48.30 \%$ had intermediate titles, and $16.84 \%$ had vice-senior or senior titles. Participants reported their education level, including technical secondary school $(1.19 \%)$, college degree (10.03\%), bachelor's degree (77.72\%), and master's degree or above (11.05\%).

Regarding COVID-19-related characteristics, 45.24\% of respondents worked in the designated hospitals, $24.49 \%$ worked in the community health centre, and $30.27 \%$ worked in other medical institutions. Of the respondents, for $22.79 \%$ the work affairs were identical to the work affairs before the pandemic, for $50.51 \%$ the work affairs were basically consistent with the previous work affairs, and for $26.70 \%$ the work affairs were inconsistent with the previous work affairs. A total of $12.76 \%$ of the participants had direct contact with confirmed patients and/or body fluid, $14.29 \%$ had possible contact with confirmed patients and/or body fluid, $6.12 \%$ had direct contact with suspected patients and/or body fluid, $40.48 \%$ had possible contact with suspected patients and/or body fluid, and $26.36 \%$ had no contact with any confirmed and suspected patients and/or body fluid. Among all participants, $82.65 \%$ had adequate protection with standard precautions, and $17.35 \%$ had inadequate protection with standard precautions. A total of $9.35 \%$ of participants currently reported a state of quarantined status, $50.51 \%$ had a burden to take care of the family, and $16.50 \%$ had work experience in response to outbreaks.

\section{Outcome Characteristics - SQQ, PSS-10 and PHQ-4}

The total mean of the SQQ score was 16.01 (95\% CI $[15.40,16.57])$. The SQQ scores were significantly 
Table I Sociodemographic Characteristics and COVID-19Related Characteristics $(\mathrm{N}=588)$

\begin{tabular}{|c|c|c|}
\hline Characteristics & & $\mathbf{N}(\%)$ \\
\hline \multicolumn{3}{|l|}{ Gender } \\
\hline & Male & $143(24.32)$ \\
\hline & Female & $445(75.68)$ \\
\hline \multicolumn{3}{|l|}{ Province } \\
\hline & Zhejiang & $355(60.37)$ \\
\hline & Hubei & $190(32.31)$ \\
\hline & Others & $43(7.31)$ \\
\hline \multicolumn{3}{|l|}{ Marital status } \\
\hline & Single & $104(17.69)$ \\
\hline & Married & $476(80.95)$ \\
\hline & Divorced & $8(1.36)$ \\
\hline & Widowed & $0(0)$ \\
\hline \multicolumn{3}{|c|}{ Occupational categories } \\
\hline & Medical doctor & $239(40.65)$ \\
\hline & Registered nurse & $266(45.24)$ \\
\hline & Medical technician & $63(10.7 I)$ \\
\hline & Administrator & $20(3.40)$ \\
\hline \multicolumn{3}{|l|}{ Professional title } \\
\hline & Unknown & $21(3.57)$ \\
\hline & Junior & $184(31.29)$ \\
\hline & Intermediate & $284(48.30)$ \\
\hline & Vice-senior or senior & $99(16.84)$ \\
\hline \multicolumn{3}{|l|}{ Educational level } \\
\hline & $\begin{array}{l}\text { Technical secondary school or } \\
\text { below }\end{array}$ & 7 (I.19) \\
\hline & College degree & $59(10.03)$ \\
\hline & Bachelor's degree & $457(77.72)$ \\
\hline & Master's degree or above & $65(11.05)$ \\
\hline \multicolumn{3}{|c|}{ Departmental function } \\
\hline & Designated hospitals & $266(45.24)$ \\
\hline & Community health centre & 144 (24.49) \\
\hline & Other medical institutions & $178(30.27)$ \\
\hline \multicolumn{3}{|c|}{ If work affairs were the same as before } \\
\hline & Identical & $134(22.79)$ \\
\hline & Basically consistent & $297(50.51)$ \\
\hline & Inconsistent & $157(26.70)$ \\
\hline \multicolumn{3}{|l|}{ Job category } \\
\hline & Direct contact confirmed patients & $75(12.76)$ \\
\hline & $\begin{array}{l}\text { Possible contact confirmed } \\
\text { patients }\end{array}$ & $84(14.29)$ \\
\hline & Direct contact suspected patients & $36(6.12)$ \\
\hline
\end{tabular}

(Continued)
Table I (Continued).

\begin{tabular}{|c|c|c|}
\hline Characteristics & & $\mathbf{N}(\%)$ \\
\hline & $\begin{array}{l}\text { Possible contact suspected } \\
\text { patients }\end{array}$ & $238(40.48)$ \\
\hline & Non-contact & $155(26.36)$ \\
\hline \multicolumn{3}{|c|}{ Adequate protection } \\
\hline & No & $102(17.35)$ \\
\hline & Yes & $486(82.65)$ \\
\hline \multicolumn{3}{|c|}{ Quarantined status currently } \\
\hline & No & $533(90.65)$ \\
\hline & Yes & $55(9.35)$ \\
\hline \multicolumn{3}{|c|}{ Have family care burden } \\
\hline & No & 291 (49.49) \\
\hline & Yes & $297(50.51)$ \\
\hline \multicolumn{3}{|c|}{ Work experience in response to outbreaks } \\
\hline & No & $491(83.50)$ \\
\hline & Yes & $97(16.50)$ \\
\hline
\end{tabular}

different by departmental function ( $\mathrm{F}=3.73, P=0.024)$, job category $(\mathrm{F}=4.02, P=0.003)$, and burden of family care $(\mathrm{F}=13.86, P<0.001)$. No significant difference was found by gender, province, marital status, occupational categories, professional title, educational level, whether work affairs were the same as before, adequate protection, quarantined status, and work experience in response to outbreaks (all $P>0.05$ ) (Table 2).

The total mean PSS score was 15.46 (95\% CI [15.05, 15.87]). The PSS scores were significantly different by province $(\mathrm{F}=7.05, P=0.001)$, occupational categories $(\mathrm{F}=$ $3.14, P=0.025)$, if work affairs were the same as before $(\mathrm{F}=$ $4.31, P=0.014)$, job category $(\mathrm{F}=3.51, P=0.008)$, adequate protection $(\mathrm{F}=14.26, P<0.001)$, and burden of family care $(\mathrm{F}=10.36, P=0.001)$. No significant difference was found by gender, marital status, professional title, educational level, quarantined status, or work experience in response to outbreaks (all $P>0.05$ ) (Table 2).

The PHQ-4 (GAD-2 and PHQ-2) scores are described separately in Table 3 . In the GAD-2, the quantities of scores from 0 to 6 were $132,123,275,22,22,6$, and 8 , accounting for $22.45 \%, 20.92 \%, 46.77 \%, 3.74 \%, 3.74 \%, 1.02 \%$, and $1.36 \%$, respectively. The positive rate of the anxiety symptoms test was $9.86 \%$ (58/588). In the PHQ-2, the quantities of scores from 0 to 6 were 154, 108, 265, 32, 16, 6, and 7, accounting for $26.19 \%, 18.37 \%, 45.07 \%, 5.44 \%, 2.72 \%$, 
Table 2 Differences Between Groups on Sleep Quality and Perceived Stress

\begin{tabular}{|c|c|c|c|}
\hline Characteristics & Mean $[95 \% \mathrm{Cl}]$ & $\boldsymbol{F}$ & $P$ \\
\hline \multicolumn{4}{|l|}{ Sleep Quality } \\
\hline Departmental function & & 3.73 & 0.024 \\
\hline Designated hospitals & $17.06[16.19,17.92]$ & & \\
\hline Community health centre & $16.24[15.09,17.38]$ & & \\
\hline Other medical institutions & $14.25[13.08,15.43]$ & & \\
\hline Job category & & 4.02 & 0.024 \\
\hline Direct contact confirmed patients & $18.64[17.03,20.25]$ & & \\
\hline Possible contact confirmed patients & $18.70[16.98,20.43]$ & & \\
\hline Direct contact suspected patients & $18.06[15.77,20.34]$ & & \\
\hline Possible contact suspected patients & $15.13[14.22,16.04]$ & & \\
\hline Non-contact & $14.14[13.07,15.21]$ & & \\
\hline Have family care burden & & 13.86 & $<0.001$ \\
\hline No & $14.72[13.9|| 5.54]$, & & \\
\hline Yes & $17.27[16.42,18.11]$ & & \\
\hline \multicolumn{4}{|l|}{ Perceived Stress } \\
\hline Province & & 7.05 & 0.001 \\
\hline Zhejiang & $14.29[13.77,|4.8|]$ & & \\
\hline Hubei & $17.14[16.43,17.84]$ & & \\
\hline Others & $17.77[16.04,19.50]$ & & \\
\hline Occupational categories & & 3.14 & 0.025 \\
\hline Medical doctor & $15.45[14.76,16.14]$ & & \\
\hline Registered nurse & $15.78[15.17,16.39]$ & & \\
\hline Medical technician & $13.75[12.50,14.99]$ & & \\
\hline Administrator & $16.85[14.63,19.07]$ & & \\
\hline If work affairs were the same as before & & 4.31 & 0.014 \\
\hline Identical & $13.95[13.12,14.78]$ & & \\
\hline Basically consistent & I5.49 [|4.9|, 16.07] & & \\
\hline Inconsistent & $16.7 \mid[15.85, \mid 7.56]$ & & \\
\hline Job category & & 3.51 & 0.008 \\
\hline Direct contact confirmed patients & $16.93[15.73,18.14]$ & & \\
\hline Possible contact confirmed patients & $17.64[16.53,18.75]$ & & \\
\hline Direct contact suspected patients & $15.39[13.57, \mid 7.21]$ & & \\
\hline Possible contact suspected patients & $|4.7|[\mid 4.08,15.34]$ & & \\
\hline Non-contact & $14.75[13.92,15.57]$ & & \\
\hline Adequate protection & & 14.26 & $<0.001$ \\
\hline No & $14.92[14.47,15.36]$ & & \\
\hline Yes & $18.06[17.00,19.12]$ & & \\
\hline Have family care burden & & 10.36 & 0.001 \\
\hline No & $14.57[13.95,15.19]$ & & \\
\hline Yes & $16.33[15.77,16.89]$ & & \\
\hline
\end{tabular}

$1.02 \%$, and $1.19 \%$, respectively. The positive rate of depression symptoms test was $10.37 \%(61 / 588)$.

The anxiety and non-anxiety symptom individuals were significantly different by province $\left(\chi^{2}=11.640, P=\right.$
$0.003)$, if work affairs were the same as before $\left(\chi^{2}=8.818\right.$, $P=0.012)$, job category $\left(\chi^{2}=15.300, P=0.004\right)$, and adequate protection $\left(\chi^{2}=8.408, P=0.004\right)$. The depression and non-depression symptom individuals were 
Table 3 Frequency of Each Score on the GAD-2 and the PHQ-2 $(\mathrm{N}=588)$

\begin{tabular}{|c|r|r|r|}
\hline Score & Frequency & Percent (\%) & Cumulative Percent (\%) \\
\hline GAD-2 & & & \\
0 & 132 & 22.45 & 22.45 \\
1 & 123 & 20.92 & 43.37 \\
2 & 275 & 46.77 & 90.14 \\
3 & 22 & 3.74 & 93.88 \\
4 & 22 & 3.74 & 97.62 \\
5 & 6 & 1.02 & 98.64 \\
6 & 8 & 1.36 & 100.0 \\
\hline PHQ-2 & & & \\
0 & 154 & 26.19 & 26.19 \\
1 & 108 & 18.37 & 44.56 \\
2 & 265 & 45.07 & 89.63 \\
3 & 32 & 5.44 & 95.07 \\
4 & 16 & 2.72 & 97.79 \\
5 & 6 & 1.02 & 98.81 \\
6 & 7 & 1.19 & 100.0 \\
\hline
\end{tabular}

Note: Scores $\geq 3$ in bold. significantly different by province $\left(\chi^{2}=17.807, P<\right.$ $0.001)$, professional title $\left(\chi^{2}=9.904, P=0.019\right)$, if work affairs were the same as before $\left(\chi^{2}=10.486, P=0.005\right)$, job category $\left(\chi^{2}=11.477, P=0.022\right)$, and adequate protection $\left(\chi^{2}=16.633, P<0.001\right)$ (Table 4).

\section{Correlational Analysis and Structural Equation Modelling}

Correlational analysis showed that there were significant correlations between perceived stress and sleep quality $(\mathrm{r}=$ $0.52, P<0.001)$, anxiety and depression and sleep quality $(\mathrm{r}=0.57, P<0.001)$, and perceived stress and anxiety and depression $(\mathrm{r}=-0.64, P<0.001)$. Good sleep quality usually indicated lower stress and fewer anxiety and depression symptoms during the COVID-19 pandemic.

Based on a priori hypotheses for building a model, perceived stress was associated with sleep quality (beta $=$ $0.25, P=0.045)$, perceived stress was associated with anxiety and depression (beta $=0.78, P=0.014$ ), and

Table 4 Comparisons Between Anxiety and Non-Anxiety Symptom as Well as Depression and Non-Depression Symptom Individuals

\begin{tabular}{|c|c|c|c|c|c|c|c|c|}
\hline \multirow[t]{2}{*}{ Characteristics } & \multicolumn{2}{|c|}{ GAD-2 } & \multirow[t]{2}{*}{$\chi^{2}$} & \multirow[t]{2}{*}{$\boldsymbol{P}$} & \multicolumn{2}{|c|}{ PHQ-2 } & \multirow[t]{2}{*}{$\chi^{2}$} & \multirow[t]{2}{*}{$\boldsymbol{P}$} \\
\hline & $<3(\%)$ & $\geq 3$ (\%) & & & $<3(\%)$ & $\geq 3$ (\%) & & \\
\hline Province & & & 11.640 & 0.003 & & & 17.807 & $<0.001$ \\
\hline Zhejiang & $332(93.52)$ & $23(6.48)$ & & & $333(93.80)$ & $22(6.20)$ & & \\
\hline Hubei & $162(85.26)$ & $28(14.74)$ & & & $160(84.21)$ & $30(15.79)$ & & \\
\hline Others & $36(83.72)$ & $7(16.28)$ & & & $34(79.07)$ & $9(20.93)$ & & \\
\hline Professional title & & & & & & & 9.904 & 0.019 \\
\hline Unknown & & & & & $17(80.95)$ & $4(19.05)$ & & \\
\hline Junior & & & & & I56 (84.78) & $28(15.22)$ & & \\
\hline Intermediate & & & & & $261(91.90)$ & $23(8.10)$ & & \\
\hline Vice-senior or senior & & & & & $93(93.94)$ & $6(6.06)$ & & \\
\hline $\begin{array}{l}\text { If work affairs were the same as } \\
\text { before }\end{array}$ & & & 8.818 & 0.012 & & & 10.486 & 0.005 \\
\hline Identical & $129(96.27)$ & $5(3.73)$ & & & $129(96.27)$ & $5(3.73)$ & & \\
\hline Basically consistent & $266(89.56)$ & $31(10.44)$ & & & $265(89.23)$ & $32(10.77)$ & & \\
\hline Inconsistent & I 35 (85.99) & $22(14.01)$ & & & I33 (84.7I) & $24(15.29)$ & & \\
\hline Job category & & & 15.300 & 0.004 & & & II.477 & 0.022 \\
\hline Direct contact confirmed patients & $64(85.33)$ & II (I4.67) & & & $63(84.00)$ & $12(16.00)$ & & \\
\hline Possible contact confirmed patients & $68(80.95)$ & $16(19.05)$ & & & $70(83.33)$ & $14(16.67)$ & & \\
\hline Direct contact suspected patients & $31(86.11)$ & $5(13.89)$ & & & $30(83.33)$ & $6(16.67)$ & & \\
\hline Possible contact suspected patients & $223(93.70)$ & $15(6.30)$ & & & $220(92.44)$ & $18(7.56)$ & & \\
\hline Non-contact & $144(92.90)$ & II (7.10) & & & $144(92.90)$ & II (7.10) & & \\
\hline Adequate protection & & & 8.408 & 0.004 & & & 16.633 & $<0.001$ \\
\hline No & $84(82.35)$ & $18(17.65)$ & & & $80(78.43)$ & $22(21.57)$ & & \\
\hline Yes & $446(91.77)$ & $40(8.23)$ & & & 447 (91.98) & $39(8.02)$ & & \\
\hline
\end{tabular}




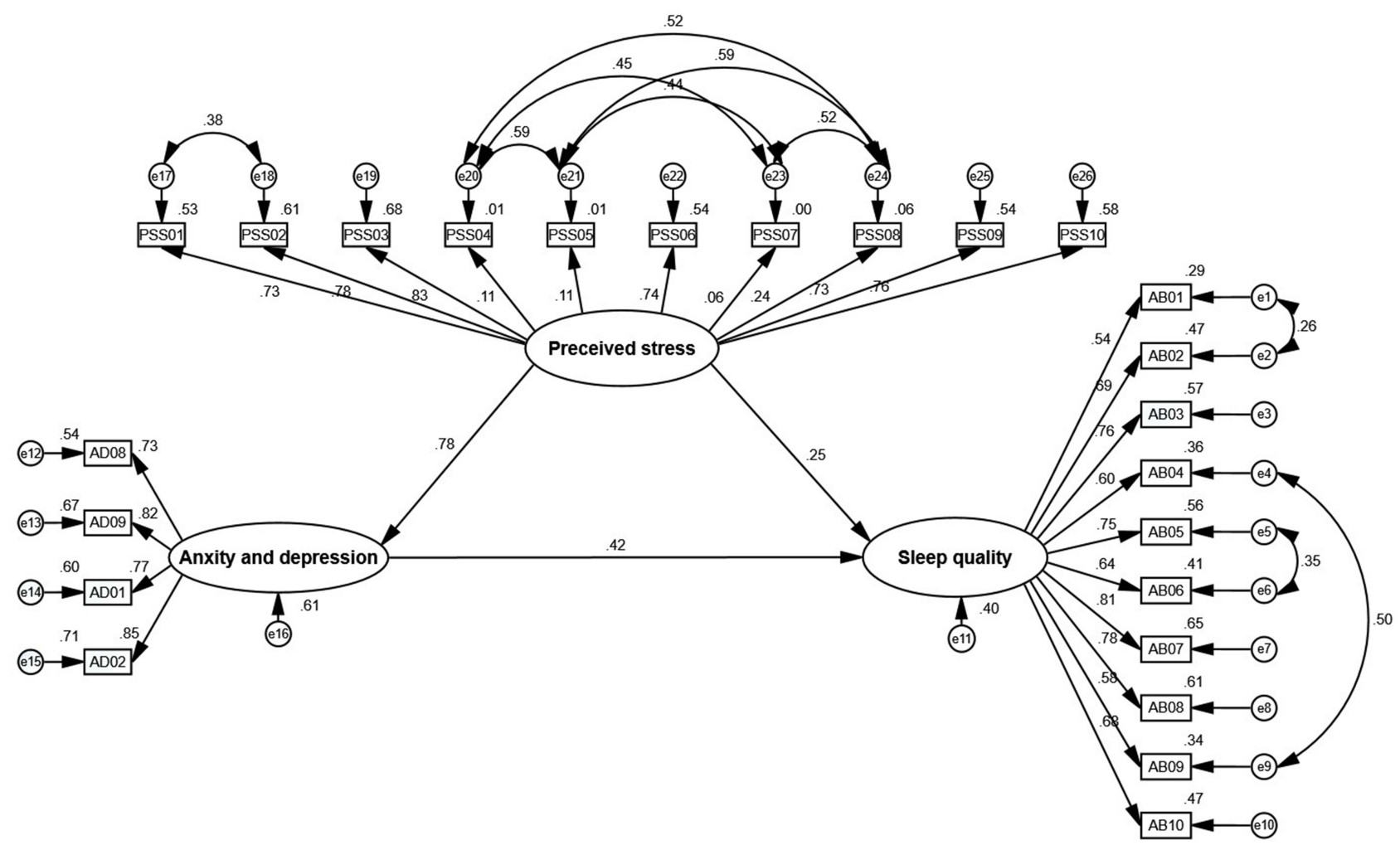

Figure I Final structural model $(\mathrm{N}=588)$.

anxiety and depression were associated with sleep quality (beta $=0.42, P<0.001$ ). The results are shown in Figure 1. All path coefficients in the model had $P<$ 0.05 . The results of the tests and the goodness-of-fit of the model are presented in Table 5.

Table 5 Evaluation of the Goodness-of-Fit of the Model $(N=588)$

\begin{tabular}{|l|r|r|r|}
\hline GOF Index & Test Result & $\begin{array}{r}\text { Recommended } \\
\text { Value }\end{array}$ & $\begin{array}{r}\text { Model } \\
\text { Fit }\end{array}$ \\
\hline Absolute measures & & & \\
RMSEA $(90 \% \mathrm{Cl})$ & $0.057(0.052$, & $<.08$ & Yes \\
SRMR & $0.062)$ & $<0.08$ & Yes \\
GFI & 0.056 & $>0.90$ & Yes \\
NC & 0.907 & $<2.0-3.0$ & Yes \\
\hline Incremental fit & 2.886 & & \\
measures & & $>0.90$ & Yes \\
TLI & 0.933 & $>0.90$ & Yes \\
CFI & 0.942 & & \\
\hline Parsimony measures & & $>0.50$ & Yes \\
PGFI & 0.723 & 0.50 & Yes \\
PNFI & 0.791 & & \\
\hline
\end{tabular}

Abbreviations: GOF, goodness-of-fit; RMSEA, root mean square error of approximation; $\mathrm{Cl}$, confidence interval; SRMR, standardized root mean residual; GFI, goodness-of-fit index; NC, normed chi-square; TLI, Tucker-Lewis index; CFI, comparative fit index; PGFI, parsimony goodness-of-fit index; PNFI, parsimony normed fit index.

\section{Discussion}

This trend is worrisome, as studies suggest that health care workers suffered from sleep dysfunction and psychological distress during the outbreak of COVID-19, especially poor sleep quality in frontline health care workers. ${ }^{3,15,21,44-48}$ This study shows that sleep quality was related to departmental function, job category, and burden of family care among health care workers. Health care workers who work in designated hospitals had poorer sleep quality than those in community health centres and other medical institutions. Health care workers who worked in relatively safe places had better sleep quality because they might not have contact with the COVID-19 patients or their body fluid. COVID-19 outbreak-associated events, such as exposure to risk factors, correlate with decreased sleep quality in relationship with an increase in negative mood. ${ }^{23}$ Health care workers who had the burden of taking care of the family had significantly worse sleep quality. In this study, we did not explore the difference between the outbreak and non-outbreak times on sleep quality among health care workers. However, another study from us found that the quality of sleep among health care workers during the outbreak was better than that during non-outbreaks, ${ }^{33}$ and whether this finding was real and its cause needs follow-up evidence. 
Studies indicate that health care workers fighting against COVID-19 are generally under stress worldwide. ${ }^{24,49-53}$ Our study shows that the perceived stress of health care workers in this outbreak was related to province, occupational categories, whether work affairs were the same as before, job category, adequate protection and burden of family care. Health care workers in Zhejiang had lower perceived stress levels than health care workers in Hubei and others, probably because Wuhan (the capital of Hubei Province) and Hubei were in the epicentre during the early stage of the epidemic. Health care workers in Wuhan were faced with various stressors, such as a shortage of medical professionals, a lack of supplies of personal protective equipment and medical devices, and a high possibility of occupational exposure; thus, their perceived stress was relatively high. Due to the large amount of coordination and management, the perceived stress of administrators was higher than that of registered nurses, medical doctors and medical technicians. Many health care workers left their original positions and stationed at the frontline during the COVID-19 outbreak, which increased their perceived stress. Health care workers who had possible contact with patients or body fluids had the highest stress, which may be due to uncertainty and inadequate protection, compared with health care workers who directly contacted confirmed patients with COVID-19. Health care workers without adequate protection had significantly higher perceived stress than those with adequate protection, and health care workers with a burden of family care had significantly higher perceived stress.

This study shows that $9.86 \%$ of health care workers in the COVID-19 response may have anxiety symptoms, and $10.37 \%$ of health care workers may have depression symptoms. Additionally, a multinational and multicentre study on the psychological outcomes among health care workers during the COVID-19 outbreak exhibited 8.7\% moderate to extremely severe anxiety, and $5.3 \%$ screened positive for moderate to very severe depression. ${ }^{54}$ Preliminary evidence in a recent review suggests that the incidence rate of anxiety and depression was $16-28 \%{ }^{55}$ The positive rate of anxiety and depression symptoms in our survey was fairly low, which could be because the surveyed respondents consisted of health care workers working in the confirmed ward and community health care workers and other health care workers who were relatively less affected by the outbreak. The anxiety and non-anxiety symptom individuals as well as depression and non-depression symptom individuals were significantly different by province, if work affairs were the same as before, job category, and adequate protection. Moreover, the depression and non-depression symptom individuals were significantly different by professional title.

Confronting an unforeseen global event due to the COVID-19 outbreak, most individuals are exposed to an unprecedented stressful situation of unknown duration, which might not only increase stress, anxiety and depression symptom levels but also decrease sleep quality. ${ }^{56}$ The final SEM model in the current study provides us with further evidence that mitigating stress and increasing coping could help reduce anxiety and depression symptoms, thereby improving the level of sleep quality among health care workers. Many health care workers from a qualitative study mentioned that they did not need a psychologist but needed more rest without interruption and enough protective supplies. ${ }^{57}$ In addition to developing targeted strategies to mitigate key stressors, the urgent need for better sleep health management strategies should be emphasized during the COVID-19 crisis. Moreover, managing sleep problems as best as possible during the COVID-19 crisis could limit perceived stress and possibly prevent disruptions of social relationships. ${ }^{56}$ The current wave of COVID-19 outbreaks, which began more than a year ago around the world, is still ongoing. To promote the mental health of health care workers, we should first put their actual needs through a stress reduction program, thereby fundamentally decreasing their anxiety and depression symptoms and improving sleep quality level. There are currently three available interventions for consideration: work interventions, psychosocial interventions, and pharmacotherapies. ${ }^{58}$ Additionally, our organizations should intensify the efforts to improve humanistic concern in case health care workers may have become overexcited in clinical work and refused reasonable rest to ensure their health. ${ }^{59}$ In addition, it is equally crucial for health care workers to maintain a balance between their needs and others' needs. ${ }^{60}$ Briefly, we highlight the role of perceived stress or work stressors and tailored interventions to mitigate poor sleep quality and prevent long-term physical and psychological implications. Nevertheless, be sure to keep in mind that the current situation during the COVID-19 outbreak will not disappear overnight and the focus should be on longer-term occupational capacity rather than repeated short-term crisis responses, based on the WHO strong recommendations. ${ }^{61,62}$ Future studies should aim to provide high-quality information on the long-term consequences and the effectiveness of applied interventions coping with COVID-19. 
There are valuable strengths and key limitations. First, this study assessed sleep quality and perceived stress and anxiety and depression symptoms among health care workers during the COVID-19 crisis and explored associated factors and their interactions, which could provide clues to help precise interventions of sleep quality and other mental health problems for health care workers. Second, the inclusion of multidisciplinary health care workers allowed for comparison between different backgrounds. Nevertheless, some limitations should be noted. First, the snowball sampling in this study generally might mean poor representativeness due to constraints on resources and conditions. Second, the sample size is comparably small to other studies in this field, and no large-scale study was carried out on severe pandemic situations at the initial stage of outbreaks. This nonrandom sampling method with small samples could limit the generalizability of these findings. Third, a crosssectional study design based on a rapid online survey cannot make valid causal inferences about the relationship between the study variables, and no follow-up data from different stages of the pandemic stages were collected, which does not allow us to analyse sleep quality and perceived stress over some time. Finally, to keep the survey time and the response rate acceptable, the sampled questions did not include some mediating and moderating variables (eg, psychological resilience, psychological capital, social support, selfcompassion, self-care, and optimism) and potential confounders $^{15}$ (eg, work shifts, work schedule, sleeping accommodations, caffeine/nicotine intake, diets, and coexisting sleep disorders).

\section{Conclusions}

Poor sleep quality and high perceived stress were common in Chinese health care workers during the COVID-19 pandemic. Reducing perceived stress could help reduce anxiety and depression symptoms, thereby improving sleep quality among health care workers. Moreover, in an attempt to promote psychological resources, we should perhaps take multiple measures, including personal tailored intervention and organizational humanistic concern.

\section{Acknowledgments}

The authors are indebted to the department heads and the participants who made the current study possible. Especially thanks to both developers and introducers of these three instruments. The authors appreciate edits on earlier drafts from Dr. Xiaoyu Lan (University of Oslo, Oslo, Norway). Moreover, they are particularly grateful for the insightful comments from three anonymous reviewers and the academic editor.

\section{Author Contributions}

All authors made a significant contribution to the work reported, whether that is in the conception, study design, execution, acquisition of data, analysis and interpretation, or in all these areas; took part in drafting, revising or critically reviewing the article; gave final approval of the version to be published; have agreed on the journal to which the article has been submitted; and agree to be accountable for all aspects of the work.

\section{Funding}

The first author was supported by the Ningbo Philosophy and Social Science Planning Project (Grant No. G20ZX66). Additionally, the last author was supported by the Research Initiation Fund of Hangzhou Normal University (Grant No. RWSK20201003).

\section{Disclosure}

The authors declare no conflicts of interest.

\section{References}

1. World Health Organization. WHO Coronavirus (COVID-19) dashboard; 2021. Available from: https://covid19.who.int/. Accessed September 10, 2021.

2. Nicola M, Alsafi Z, Sohrabi C, et al. The socio-economic implications of the coronavirus pandemic (COVID-19): a review. Int J Surg. 2020;78:185-193. doi:10.1016/j.ijsu.2020.04.018

3. Herrero San Martin A, Parra Serrano J, Diaz Cambriles T, et al. Sleep characteristics in health workers exposed to the COVID-19 pandemic. Sleep Med. 2020;75:388-394. doi:10.1016/j.sleep.2020. 08.013

4. Pappa S, Sakkas N, Sakka E. A year in review: sleep dysfunction and psychological distress in healthcare workers during the COVID-19 pandemic. Sleep Med. 2021. doi:10.1016/j.sleep.2021.07.009

5. Mehta S, Machado F, Kwizera A, et al. COVID-19: a heavy toll on health-care workers. Lancet Respir Med. 2021;9(3):226-228. doi:10. 1016/S2213-2600(21)00068-0

6. Papoutsi E, Giannakoulis VG, Ntella V, Pappa S, Katsaounou P. Global burden of COVID-19 pandemic on healthcare workers. ERJ Open Res. 2020;6(2):00195-02020. doi:10.1183/23120541.001952020

7. Stewart NH, Koza A, Dhaon S, Shoushtari C, Martinez M, Arora VM. Sleep disturbances in frontline health care workers during the COVID-19 pandemic: social media survey study. J Med Internet Res. 2021;23(5):e27331. doi:10.2196/27331

8. Mendonça F, Mostafa SS, Morgado-Dias F, Ravelo-García AG, Penzel T. A review of approaches for sleep quality analysis. IEEE Access. 2019;7:24527-24546. doi:10.1109/ACCESS.2019.2900345

9. Guest C, Guest DD, Smith-Coggins R. How to care for the basics: sleep, nutrition, exercise, and health. In: Roberts LW, editor. Roberts Academic Medicine Handbook: A Guide to Achievement and Fulfilment for Academic Faculty. Cham: Springer International Publishing; 2020:571-580. 
10. Matsumoto Y, Uchimura N, Ishida T, et al. Reliability and validity of the 3 dimensional sleep scale (3DSS)-day workers version-in assessing sleep phase, quality, and quantity. Sangyo Eiseigaku Zasshi. 2014;56(5):128-140. doi:10.1539/sangyoeisei.B13012

11. Buysse DJ. Sleep health: can we define it? Does it matter? Sleep. 2014;37(1):9-17. doi:10.5665/sleep.3298

12. Kline C. Sleep quality. In: Gellman MD, Turner JR, editors. Encyclopedia of Behavioral Medicine. New York, NY: Springer New York; 2013:1811-1813.

13. Medic G, Wille M, Hemels ME. Short- and long-term health consequences of sleep disruption. Nat Sci Sleep. 2017;9:151-161. doi:10.2147/NSS.S134864

14. LeBlanc VR. The effects of acute stress on performance: implications for health professions education. Acad Med. 2009;84(10):S25-S33. doi:10.1097/ACM.0b013e3181b37b8f

15. Jahrami H, BaHammam AS, AlGahtani H, et al. The examination of sleep quality for frontline healthcare workers during the outbreak of COVID-19. Sleep Breathing. 2021;25(1):503-511. doi:10.1007/ s11325-020-02135-9

16. Kucharczyk ER, Morgan K, Hall AP. The occupational impact of sleep quality and insomnia symptoms. Sleep Med Rev. 2012;16 (6):547-559. doi:10.1016/j.smrv.2012.01.005

17. Mulfinger N, Sander A, Stuber F, et al. Cluster-randomised trial evaluating a complex intervention to improve mental health and well-being of employees working in hospital - a protocol for the SEEGEN trial. BMC Public Health. 2019;19(1):1694. doi:10.1186/s12889-019-7909-4

18. Hall H. The effect of the COVID-19 pandemic on healthcare workers' mental health. J Am Acad Physician Assist. 2020;33(7):45-48. doi:10.1097/01.JAA.0000669772.78848.8c

19. Lin YN, Liu ZR, Li SQ, et al. Burden of sleep disturbance during COVID-19 pandemic: a systematic review. Nat Sci Sleep. 2021;13:933. doi:10.2147/NSS.S312037

20. Pappa S, Ntella V, Giannakas T, Giannakoulis VG, Papoutsi E, Katsaounou P. Prevalence of depression, anxiety, and insomnia among healthcare workers during the COVID-19 pandemic: a systematic review and meta-analysis. Brain Behav Immun. 2020;88:901-907. doi:10.1016/j.bbi.2020.05.026

21. Zheng Y, Wang L, Feng L, Ye L, Zhang A, Fan R. Sleep quality and mental health of medical workers during the coronavirus disease 2019 pandemic. Sleep Biol Rhythms. 2021;19(2):173-180. doi:10. 1007/s41105-020-00304-7

22. Zhang C, Yang L, Liu S, et al. Survey of insomnia and related social psychological factors among medical staff involved in the 2019 novel coronavirus disease outbreak. Front Psychiatry. 2020;11:306. doi:10.3389/fpsyt.2020.00306

23. Targa ADS, Benítez ID, Moncusí-Moix A, et al. Decrease in sleep quality during COVID-19 outbreak. Sleep Breathing. 2021;25 (2):1055-1061. doi:10.1007/s11325-020-02202-1

24. Mo Y, Deng L, Zhang L, et al. Work stress among Chinese nurses to support Wuhan in fighting against COVID-19 epidemic. J Nurs Manag. 2020;28(5):1002-1009. doi:10.1111/jonm.13014

25. Vanhaecht K, Seys D, Bruyneel L, et al. COVID-19 is having a destructive impact on health-care workers' mental well-being. Int J Qual Health Care. 2020;33(1):mzaa158. doi:10.1093/intqhe/mzaa158

26. Magnavita N, Tripepi G, Di Prinzio RR. Symptoms in health care workers during the COVID-19 epidemic. A Cross-sectional survey. Int J Environ Res Public Health. 2020;17(14):5218-5232. doi:10. 3390/ijerph17145218

27. Magnavita N, Di Prinzio RR, Chirico F, Sacco A, Quintavalle G. COVID-19 and staff mental health: is there an evidence? An Italian field study. Eur J Public Health. 2020;30(Supplement_5):ckaa165. 565. doi:10.1093/eurpub/ckaa165.565

28. Garbarino S, Magnavita N. Sleep problems are a strong predictor of stress-related metabolic changes in police officers. A prospective study. PLoS One. 2019;14(10):e0224259. doi:10.1371/journal.pone. 0224259
29. Shreffler J, Petrey J, Huecker M. The impact of COVID-19 on healthcare worker wellness: a scoping review. West J Emergency Med. 2020;21(5):1059-1066. doi:10.5811/westjem.2020.7.48684

30. Magnavita N, Garbarino S. Sleep, health and wellness at work: a scoping review. Int $J$ Environ Res Public Health. 2017;14 (11):1347-1364. doi:10.3390/ijerph14111347

31. Arnab R. Chapter 26 - sampling rare and mobile populations. In: Arnab R, editor. Survey Sampling Theory and Applications. London, San Diego, Cambridge, Oxford: Academic Press; 2017:821-857.

32. Kato T. Development of the sleep quality questionnaire in healthy adults. J Health Psychol. 2014;19(8):977-986. doi:10.1177/135910 5313482168

33. Meng R. Development and Evaluation of the Chinese Version of the Sleep Quality Questionnaire. Wuhan: Wuhan University; 2020.

34. Meng R, Kato T, Mastrotheodoros S, et al. Adaptation and Validation of the Chinese Version of the Sleep Quality Questionnaire. Hangzhou: Hangzhou Normal University; 2021.

35. Cohen S, Kamarck T, Mermelstein R. A Global Measure of perceived stress. J Health Soc Behav. 1983;24(4):385-396. doi:10.2307/213 6404

36. Lee E-H. Review of the psychometric evidence of the perceived stress scale. Asian Nursing Res. 2012;6(4):121-127. doi:10.1016/j. anr.2012.08.004

37. Wang Z, Chen J, Boyd JE, et al. Psychometric properties of the Chinese version of the perceived stress scale in policewomen. PLoS One. 2011;6(12):e28610. doi:10.1371/journal.pone.0028610

38. Spitzer RL, Kroenke K, Williams JBW, Group at PHQPCS. Validation and utility of a self-report version of PRIME-MDThe PHQ primary care study. JAMA. 1999;282(18):1737-1744. doi:10.10 01/jama.282.18.1737

39. Kroenke K, Spitzer RL, Williams JBW, Löwe B. An ultra-brief screening scale for anxiety and depression: the PHQ-4. Psychosomatics. 2009;50(6):613-621.

40. Kline RB. Principles and Practice of Structural Equation Modeling. New York, NY: Guilford publications; 2016.

41. Hair JF, Black WC, Babin BJ, Anderson RE. Multivariate Data Analysis: Pearson New International Edition. 7th ed. London: Pearson Higher Education; 2014.

42. Mulaik SA, James LR, Van Alstine J, Bennett N, Lind S, Stilwell CD. Evaluation of goodness-of-fit indices for structural equation models. Psychol Bull. 1989;105(3):430-445. doi:10.1037/0033-2909.105.3.430

43. World Medical Association. World Medical Association Declaration of Helsinki: ethical principles for medical research involving human subjects. JAMA. 2013;310(20):2191-2194. doi:10.1001/jama.2013. 281053

44. Marvaldi M, Mallet J, Dubertret C, Moro MR, Guessoum SB. Anxiety, depression, trauma-related, and sleep disorders among healthcare workers during the COVID-19 pandemic: a systematic review and meta-analysis. Neurosci Biobehav Rev. 2021;126: 252-264. doi:10.1016/j.neubiorev.2021.03.024

45. De Kock JH, Latham HA, Leslie SJ, et al. A rapid review of the impact of COVID-19 on the mental health of healthcare workers: implications for supporting psychological well-being. BMC Public Health. 2021;21(1):104. doi:10.1186/s12889-020-10070-3

46. Than HM, Nong VM, Nguyen CT, et al. Mental health and health-related quality-of-life outcomes among frontline health workers during the peak of COVID-19 outbreak in vietnam: a cross-sectional study. Risk Manag Healthc Policy. 2020;13:2927-2936. doi:10.2147/ RMHP.S280749

47. Qi J, Xu J, Li B-Z, et al. The evaluation of sleep disturbances for Chinese frontline medical workers under the outbreak of COVID-19. Sleep Med. 2020;72:1-4. doi:10.1016/j.sleep.2020.05.023

48. Xia L, Chen C, Liu Z, et al. Prevalence of sleep disturbances and sleep quality in Chinese healthcare workers during the COVID-19 pandemic: a systematic review and meta-analysis. Front Psychiatry. 2021;12:149. doi:10.3389/fpsyt.2021.646342 
49. Rana W, Mukhtar S, Mukhtar S. Mental health of medical workers in Pakistan during the pandemic COVID-19 outbreak. Asian J Psychiatr. 2020;51:102080. doi:10.1016/j.ajp.2020.102080

50. Wang $\mathrm{H}$, Liu $\mathrm{Y}, \mathrm{Hu} \mathrm{K}$, et al. Healthcare workers' stress when caring for COVID-19 patients: an altruistic perspective. Nurs Ethics. 2020;27(7):1490-1500. doi:10.1177/096973302093 4146

51. Abbas S, Al-Abrrow H, Abdullah HO, Alnoor A, Khattak ZZ, Khaw KW. Encountering Covid-19 and perceived stress and the role of a health climate among medical workers. Current Psychol. 2021. doi:10.1007/s12144-021-01381-8

52. Babore A, Lombardi L, Viceconti ML, et al. Psychological effects of the COVID-2019 pandemic: perceived stress and coping strategies among healthcare professionals. Psychiatry Res. 2020;293:113366. doi:10.1016/j.psychres.2020.113366

53. Chua GT, Tung KTS, Kwan MYW, et al. Multilevel factors affecting healthcare workers' perceived stress and risk of infection during COVID-19 pandemic. Int J Public Health. 2021;66(8):599408. doi:10.3389/ijph.2021.599408

54. Chew NWS, Lee GKH, Tan BYQ, et al. A multinational, multicentre study on the psychological outcomes and associated physical symptoms amongst healthcare workers during COVID-19 outbreak. Brain Behav Immun. 2020;88:559-565. doi:10.1016/j. bbi.2020.04.049

55. Rajkumar RP. COVID-19 and mental health: a review of the existing literature. Asian J Psychiatr. 2020;52:102066. doi:10.1016/j.ajp.20 20.102066
56. Altena E, Baglioni C, Espie CA, et al. Dealing with sleep problems during home confinement due to the COVID-19 outbreak: practical recommendations from a task force of the European CBT-I academy. J Sleep Res. 2020;29(4):e13052. doi:10.1111/jsr.13052

57. Chen Q, Liang M, Li Y, et al. Mental health care for medical staff in China during the COVID-19 outbreak. Lancet Psychiatry. 2020;7(4): e15-e16. doi:10.1016/S2215-0366(20)30078-X

58. Cabarkapa S, King JA, Ng CH. The psychiatric impact of COVID-19 on healthcare workers. Aust J Gen Pract. 2020;49(12):791-795. doi:10.31128/AJGP-07-20-5531

59. National Health Commission of the PRC. The guidelines for emergency psychological crisis interventions for the COVID-19 Pneumonia; 2020. Available from: http://www.nhc.gov.cn/jkj/s3577/202001/ 6adc08b966594253b2b791be5c3b9467.shtml. Accessed March 30, 2021.

60. Waris Nawaz M, Imtiaz S, Kausar E. Self-care of frontline health care workers: during COVID-19 pandemic. Psychiatr Danub. 2020;32(3-4):557-562. doi:10.24869/psyd.2020.557

61. World Health Organization. Mental Health and Psychosocial Considerations During the COVID-19 Outbreak. Geneva, Switzerland: World Health Organization; March 18, 2020.

62. Lee ES, Tan SY, Lee PSS, et al. Perceived stress and associated factors among healthcare workers in a primary healthcare setting: the psychological readiness and occupational training enhancement during COVID-19 time (PROTECT) study. Singapore Med J. 2020;1:25.

\section{Publish your work in this journal}

Nature and Science of Sleep is an international, peer-reviewed, open access journal covering all aspects of sleep science and sleep medicine, including the neurophysiology and functions of sleep, the genetics of sleep, sleep and society, biological rhythms, dreaming, sleep disorders and therapy, and strategies to optimize healthy sleep.
The manuscript management system is completely online and includes a very quick and fair peer-review system, which is all easy to use. Visit http://www.dovepress.com/testimonials.php to read real quotes from published authors. 